\title{
Un Cuento de Borges: "La Casa de Asterión"
}

Jorge Luis Borges (Argentina; 1899), que hace pocos años era un escritor de minorías, apenas leído en su propio país, ha venido conquistando un público cada vez más vasto hasta colocar su obra en el foco de la atención internacional. Hoy se reconoce a Borges como uno de los escritores más interesantes de nuestro tiempo, traducido y estudiado en varias lenguas. Este éxito, que es un merecido premio a su talento, prueba también que aun la literatura más difícil puede convertirse en popular cuando halaga la necesidad deportiva de novedad. Todos agradecemos al escritor que nos excita con una contínua sucesión de imprevistos cambios. Nuestra existencia fluye en el tiempo. Si nuestra conciencia temporal se nos vacía, caemos en el aburrimiento. Nos divierte, por el contrario, toda experiencia que nos obliga a esperar. Y cuando un cuento, pongamos por caso, va activando nuestra mente con tensiones y distensiones, ocultamientos y revelaciones, preguntas y respuestas, problemas y soluciones, sentimos que ese cuento tiene la forma interior de un pasatiempo. Aceptamos el desafío y nos ponemos a la expectativa. La fruición de un cuento aumenta, pues, con el análisis de su estructura. En Borges es tan imperiosa la voluntad de jugar con el lector a acertijos de leyes estrictas que en la relectura es cuando más se lo disfruta. Si no el más leído, es sin duda uno de los escritores más releídos de nuestra literatura. Nos proponemos a continuación, analizar uno de sus cuentos. No es el mejor de Borges. Ni siquiera es uno de los diez mejores. Pero, por ser breve, se presta a que podamos escudriñarlo en los límites de un breve ensayo. Antes leámoslo: 


\title{
La CASA de Asterión
}

\author{
"Y la reina dio a luz un hijo que se llamó Asterión". \\ Apolodoro: Biblioteca, III, 1
}

Sé que me acusan de soberbia, y tal vez de misantropía, y tal vez de locura. Tales acusaciones (que yo castigaré a su debido tiempo) son irrisorias. Es verdad que no salgo de mi casa, pero también es verdad que sus puertas (cuyo número es infinito) 1 están abiertas día y noche a los hombres y también a los animales. Que entre el que quiera. No hallará pompas mujeriles aquí ni el bizarro aparato de los palacios pero sí la quietud y la soledad. Asimismo hallará una casa como no hay otra en la faz de la tierra. (Mienten los que declaran que en Egipto hay una parecida). Hasta mis detractores admiten que no hay un solo mueble en la casa. Otra especie ridícula es que yo, Asterión, soy un prisionero. ¿Repetiré que no hay una puerta cerrada, añadiré que no hay cerradura? Por lo demás, algún atardecer he pisado la calle; si antes de la noche volví, lo hice por el temor que me infundieron las caras de la plebe, caras descoloridas y aplanadas como la mano abierta. Ya se había puesto el sol, pero el desvalido llanto de un niño y las toscas plegarias de la grey dijeron que me habian reconocido. La gente oraba, huía, se prosternaba; unos se encaramaban al estilóbato del templo de las Hachas, otros juntaban piedras. Alguno creo, se ocultó bajo el mar. No en vano fue una reina mi madre; no puedo confundirme con el vulgo, aunque mi modestia lo quiera.

El hecho es que soy único. No me interesa lo que un hombre pueda transmitir a otros hombres; como el filósofo, pienso que nada es comunicable por el arte de la escritura. Las enojosas y triviales minucias no tienen cabida en mi espiritu, que está capacitado para lo grande; jamás he retenido la diferencia entre una letra y otra. Cierta impaciencia generosa no ha consentido que yo aprendiera a leer. A veces lo deploro, porque las noches y los días son largos.

Claro que no me faltan distracciones. Semejante al carnero que va a embestir, corro por las galerías de piedra hasta rodar al suelo, mareado. Me agazapo a la sombra de un aljibe o a la vuelta de un corredor y juego a que me buscan. Hay azoteas desde las que me dejo caer, hasta ensangrentarme. A cualquier hora puedo jugar a estar dormido, con los ojos cerrados y la respiración poderosa. (A veces me duermo realmente, a veces ha cambiado el color del día cuando he abierto los ojos). Pero de tantos juegos el que prefiero es el de otro Asterión. Finjo que viene a visitarme y que yo le muestro la casa. Con grandes reverencias le digo: Abora volvemos a la encrucijada anterior o Abora desembocamos en otro patio o Bien decia yo que te gustaria la canaleta o Abora verás una cisterna que se llenó de arena o Ya verás cómo el sótano se bifurca. A veces me equivoco y nos reimos buenamente los dos.

1 El original dice catorce, pero sobran motivos para inferir que, en boca de Asterión, ese adietivo numeral vale por infinitos. 
No sólo he imaginado esos juegos; también he meditado sobre la casa. Todas las partes de la casa están muchas veces, cualquier lugar es otro lugar. No hay un aljibe, un patio, un abrevadero, un pesebre; son catorce (son infinitos) los pesebres, abrevaderos, patios, aljibes. La casa es del tamaño del mundo; mejor dicho, es el mundo. Sin embargo a fuerza de fatigar patios con un aljibe y polvorientas galerias de piedra gris he alcanzado la calle y he visto el templo de las Hachas y el mar. Eso no lo entendí hasta que una visión de la noche me reveló que también son catorce (son infinitos) los mares y los templos. Todo está muchas veces, catorce veces, pero dos cosas hay en el mundo que parecen estar una sola vez: arriba, el intrincado sol; abajo, Asterión. Quizá yo he creado las estrellas y el sol y la enorme casa, pero ya no me acuerdo.

Cada nueve años entran en la casa nueve hombres para que yo los libre de todo mal. Ó́go sus pasos o su voz en el fondo de las galerías de piedra y corro alegremente a buscarlos. $\mathrm{La}$ ceremonia dura pocos minutos. Uno tras otro caén sin que yo me ensangriente las manos. Donde cayeron, quedan y los cadáveres ayudan a distinguir una galería de las otras. Ignoro quiénes son, pero sé que uno de ellos profetizó, en la hora de su muerte, que alguna vez llegaría mi redentor. Desde entonces no me duele la soledad, porque sé que vive mi redentor y al fin se levantará sobre el polvo. Si mi oído alcanzara todos los rumores del mundo, yo percibiría sus pasos. Ojalá me lleve a un lugar con menos galerías y menos puertas. ¿Cómo será mi redentor?, me pregunto. ¿Será un toro o un hombre? ¿Será tal vez un toro con cara de hombre? ¿O será como yo?

El sol de la mañana reverberó en la espada de bronce. Ya no quedaba ni un vestigio de sangre. fendió,

- ¿Lo creerás, Ariadna? - dijo Teseo--. El Minotauro apenas se de-

(El Aleph, Buenos Aires: Editorial Losada, 1949; segunda edición, 1952).

\section{ESTRIJCTURA}

Es posible que un conocedor de los clásicos descifre la charada al comienzo mismo, al leer el epígrafe de Apolodoro. Es posible que un crítico, aunque desconozca quién es ese Asterión al que se refiere Apolodoro, pueda imaginarlo por las insinuaciones del texto. Pero en la mayoría de los casos ¿no es verdad que el lector se sorprende cuando, en las últimas líneas, en las palabras de Teseo a Ariadna, descubre que lo que ha leido es nada menos que la autobiografía del Minotauro?

La casa de Asterión, a pesar de su brevedad, consta de tres partes: I) el epígrafe de Apolodoro, que nos da la clave para reconocer al protagonista 2) el cuento en sí, puesto en boca del Minotauro pero sin decirnos 
que se trata del Minotauro; y 3) las palabras finales de Teseo, que resuelven el misterio.

Obsérvense, en esas tres partes, las personas que hablan y los tiempos verbales que usan. En la primera parte, el verbo inicial es dio: una tercera persona, Apolodoro, informa sobre un nacimiento pretérito. En la segunda parte, el verbo inicial es sé: una primera persona, el Minotauro, cuenta su vida presente. En la tercera parte, el verbo final es se defendió: una tercera persona, Teseo, da noticias de una muerte pretérita.

\section{EL MITO}

El mito del Minotauro es conocidísimo. ¿Con qué disfraz se nos ha escapado, mientras leíamos La casa de Asterión? Engañar, Borges no nos ha engañado. Suministró todos los datos para que pudiéramos anticipar. nos al desenlace. Comenzó por darnos la clave en el epígrafe de Apolodoro. En La Biblioteca, atribuida a Apolodoro de Atenas (c.I44 a. de C.), se nos cuenta el mito del Minotauro. Ese mito de la civilización cretense procede de los tiempos de Minos II, a mediados del siglo XIII a. de C. ${ }^{2}$ De reconocer el mito, La casa de Asterión no nos hubiese asombrado. ¿Cómo hizo Borges para mantenernos a oscuras hasta la última línea? Sencillamente, ${ }_{2}$ adoptó el procedimiento de las adivinanzas: mostró todas las claves pero las únicas palabras que no mencionó fueton, precisamente, laberinto y Minotauro. "Casa" es el nombre que se da al laberinto. "Asterión" es el nombre que se da al Minotauro. Circunloquios

2 He aquí un resumen de los pasajes pertinentes de La Biblioteca: Minos II, para probar que los dioses lo habían destinado a reinar en Creta, rogó a Posidón que, desde el abismo, le enviase un toro, y le prometió inmolarlo. Recibió el toro, blanco y tan hermoso que Minos no lo quiso inmolar. Entonces Posidón, irritado, encendió en Pasife, mujer de Minos, una ardiente pasión por la bestia. Del ayuntamiento del toro con Pasife nació Asterio, llamado el Minotauro. Tenía cara taurina pero el resto de su cuerpo era humano. El Minotauro vivía en el Laberinto, construido por Dédalo. Más tarde Minos impuso a los atenienses un tributo de siete donceles y siete doncellas para que el Minotauro los sacrificase. Teseo fue uno de los que, en el tercer tributo, debía ser sacrificado, pero Ariadna, hija de Minos, se enamoró de él y le dio una espada y un ovillo de hilo: con la espada Teseo mató al Minotauro, con el hilo, que había desovillado mientras avanzaba por el Laberinto, pudo rehacer sus pasos y encontrar la salida.

3 En otro de los cuentos de Borges - "El jardín de senderos que se bifurcan" - ocurre este diálogo: 
retóricos, pues, son los que indican la solución de la adivinanza. Veamos con qué rodeos Borges va describiendo la situación de su cuento.

\section{DESCRIPCIÓN DEL LABERINTO}

"Es verdad que no salgo de mi casa, pero también es verdad que sus puertas (cuyo número es infinito *) están abiertas día y noche a los hombres y también a los animales. Que entre el que quiera.* El original dice catorce pero sobran motivos para inferir que, en boca de Asterión, ese adjetivo numeral vale por "infinitos". Catorce es el número de los siete mancebos más las siete damiselas of rendados, según el mito, al Minotauro." "Que entre el que quiera" es una definición a medias del laberinto: la otra mitad sería "salsipuedes". Un laberinto es laberinto no porque no se pueda entrar sino porque no se puede salir.

"No hay un solo mueble en la casa". El subrayado es ambiguo: podría sugerir que no hay un mueble solo, sino muchos; lo que quiere decir es que no hay ninguno. Siendo el mueble para uso exclusivo de los hombres, con esa frase se avisa que no es humano quien vive allí.

"Unos se encaramaban al estilóbato del templo de las Hachas... Alguno, creo, se ocultó bajo el mar". El paisaje marino corresponde a la isla de Creta. El templo de las Hachas es una metonimia por laberinto. El mismo Borges, en Manual de Zoología fantástica (México: Breviarios del Fondo de Cultura Económica, I957, "El Minotauro", pp. IOI-IO2) habla del "culto del toro y de la doble hacha (cuyo nombre era labrys, que luego pudo dar laberinto".

"Asimismo hallará una casa como no hay otra en la faz de la tierra. (Mienten los que declaran que en Egipto hay una parecida)". La negación apasionada y polémica de que haya otra casa igual es alusión al laberinto que mandó construir Amenemhat III, faraón de la XII dinastía que vivió alrededor de 2300 a. de C. (Es el labetinto que describieron Herodoto y Plinio el Viejo). bida?

- En una adivinanza cuyo tema es el ajedrez ¿cuál es la única palabra prohi-

Reflexioné un momento y repuse:

- La palabra ajedrez.

En "Sobre el Vathek de William Beckford" (en Otras inquisiciones, Buenos Aires, 1952) recuerda que Carlyle bromeaba con la idea de una biografía de Miguel Angel que omitiera toda mención de las obras de Miguel Angel.

4 . La idea de que a cada persona le está destinada una puerta y que, detrás de cada puerta hay infinitas puertas, viene de Kafka y otros autores a quienes Borges cita en "sobre Chesterton", ensayo publicado el mismo año del cuento que analizamos (véase Otras inquisiciones). 
"Corro por las galerías de piedra hasta rodar al suelo, mareado"; "vuelta de un corredor"; "azoteas desde las que me dejo caer"; "volvemos a la encrucijada anterior"; "desembocamos en otro patio"; "ya verás cómo el sótano se bifurca"; "Todas las partes de la casa están muchas veces, cualquier lugar es otro lugar. No hay un aljibe, un patio, un abrevadero, un pesebre; son catorce (son infinitos) los pesebres, abrevaderos, patios, aljibes"; "Los cadáveres ayudan a distinguir una galeria de otra": todas estas pinceladas van completando la descripción del laberinto.

\section{Descripción del Minotauro}

Aunque oblicuos, los siguientes rasgos son también suficientes:

"Por lo demás, algún atardecer he pisado la calle; si antes de la noche volví, lo hice por el temor que me infundieron las caras de la plebe, caras descoloridas y aplanadas, como la mano abierta". Vista con los ojos de una prominente y pigmentada cabeza de toro, la cara humana parece descolorida y aplanada; el recelo del protagonista-narrador es el que todo animal de una especie siente por el de otra.

". . el desvalido llanto de un niño y las toscas plegarias de la grey dijeron que me habian reconocido". Llanto, plegarias de hombres ante un espantoso enemigo.

"No en vano fue una reina mi madre". Se refuerza la clave del epígrafe atribuido a Apolodoro.

"El hecho es que soy único". El adjetivo "único", que al pronto sonó a jactancia, señala en verdad el hecho objetivo de que no hay otro monstruo igual. Las distracciones, los juegos del Minotauro son los de un solitario: "Pero de tantos juegos el que prefiero es el de otro Asterión. Finjo que viene a visitarme y que yo le mucstro la casa". El brío de esta distracción, de este juego del Minotauro consiste, precisamente, en que es pura fantasía: por ser impar, es imposible otro Asterión.

"Semejante al carnero que va a embestir". El Minotauro no compara solamente las embestidas, sino también los cuernos. Comparación de cor. núpeto con cornúpeto que es más cabal de lo que dió a entender a la primera lectura.

"Abrevadero", "pesebre": o sea, las comodidades de una bestia.

"Cada nueve años entran en la casa nueve hombres para que yo los 
libere de todo mal".5 En el "Padre Nuestro" la fórmula "Líbranos de todo mal" se refiere al pecado. Para el Minotauro el mal es la vida: librar a los hombres de todo mal es un eufemismo por matarlos.

"La ceremonia dura pocos minutos". Ceremonia del sacrificio lustral.

"Uno tras otro caen sin que yo me ensangtiente las manos". Las manos limpias de sangre no prueban la inocencia del protagonista-narrador: sus cuernos son los que se ensangrientan.

"¿Será un toro o un hombre? ¿Será tal vez un toro con cara de hombre? ¿O será como yo?" Con estas últimas líneas de la autobiografía la figura del narrador queda desenmascarada: por eliminación tiene que ser un hombre con cara de toro. ${ }^{6}$

\section{EL PUNTO DE VISTA}

Además de estas descripciones perifrásticas del Laberinto y el Minotauro, despista Borges al lector con una serie de estratagemas. La mayor: haber puesto el relato en la monstruosa boca del Minotauro. El cuento comienza: "Sé que me acusan de soberbia". No se nos ocurre que una bestia pueda tener un "yo" narrativo: la tradición nos ha dado siempre el punto de vista de Teseo. Ahora, inesperadamente, el héroe es el Minotauro. ¿Cómo le vino a Borges esta idea de completar el doble destino del mito dándonos también la autobiografía del Minotauro?

\section{Simpatia POR El Minotauro}

Dice Borges en el epílogo a El Aleph: "a una tela de Watts, pintada

5 En las leyendas del ciclo minoico el número nueve recurre varias veces: el tributo al Minotauro ¿es anual durante nueve años o se cumple cada nueve años? Hay diferentes versiones. Como quiera que sea ¿de dónde sacó Borges que entran en la casa nueve hombres? En 1959 lo consulté personalmente sobre este punto y me respondió que ya se había olvidado del cuento y que era muy posible que eso de los nueve hombres fuera un descuido.

6 En "Abenjacán el Bojarí, muerto en su laberinto" (publicado originalmente en Sur, agosto de 1951, Núm. 202 y tecogido en la segunda edición de El Alepb) se discute el mito del "laberinto cuyo centro era un hombre con cabeza de toro". "Cabeza de toro tiene en medallas y esculturas el Minotauro. Dante lo imaginó con cuerpo de toro y cabeza de hombre". En el capitulillo sobre "El Minotauro" (en el ya citado Manual de Zoología fantástica) Borges agrega estas noticias: "Ovidio, en un pentámetro que trata de ser ingenioso, habla del bombre mitad toro y toro mitad bombre; Dante, que conocía las palabras de los antiguos pero no sus monedas y monumentos, imaginó al minotauro con cabeza de hombre y cuerpo de toro". Borges, pues, describe al Minotauro siguiendo La Biblioteca atribuida a Apolodoro: "Tenía cara taurina, pero el resto de su cuerpo era humano". 
en I896, debo La casa de Asterión y el carácter del pobre protagonista". Es muy probable que Borges vio la reproducción del cuadro en el libro de G. K. Chesterton, G. F.W Watts, London, I904. Sabemos que leyó este libro porque lo cita por lo menos cinco veces en ocasiones distintas en Otras inquisictones. Chesterton habla de la "brutalidad boba" del Minotauro de Watts y lo interpreta como una reacción moral, entre estoica y puritana, contra las crueldades de la ciudad moderna. En otras biografías de Watts (v. gr., la de Loftus Hare, de r9r5) se recuerda que pintó el Minotauro en tres horas, inflamado de indignación por la codicia y voracidad de la civilización materialista de nuestro tiempo. Ignoramos si Borges alcanzó a distinguir que el monstruo, en la tela de Watts, ha aplastado con su manaza un pájaro, y parece mirar hacia el mar en espera de otras bellas víctimas. Lo cierto es que Borges vio la reproducción del cuadro y pensó en otro símbolo, no moral, sino metafísico, como se verá más adelante. Se instaló con simpatía, con compasión, dentro del monstruo. Repárese en su piadoso adjetivo: "el carácter del pobre protagonista". Borges lo vio solitario, en lo alto de un parapeto de su laberinto, soñador, melancólico, contemplando el mar y como esperando. Esperando ¿qué?' Esperando a su redentor: "Sé que uno de ellos profetizó, en la hora de su muerte, que alguna vez llegaria mi redentor. Desde entonces no me duele la soledad". Lo que le habrán profetizado es que vendrá su victimario, quien lo redimirá de su fiero destino. Pero el Minotauro interpreta la redención de otro modo. El no se siente monstruo: está orgulloso de ser único, como el sol. Asterio, hijo del sol. Cree que el redentor le traerá amor y lo sacará de su laberinto. "Ojalá me lleve a un lugar con menos galerías y menos puertas". Por eso, porque el Minotauro espera un redentor amigo, acaso afín, "apenas se defendió" cuando Teseo le clavó la espada.

El carácter del Minotauro es conmovedor. Le hieren las acusaciones (de soberbia, misantropía y locura). No es un prisionero, dice. Si se refugia en el laberinto es porque los hombres lo asustan: "volví... por el temor que me infundieron las caras de la plebe". Por ser único vive desolado. Su entretenimiento es desdoblarse como un solipsista neurótico y hablar consigo mismo ¿Que oye pasos o voces?: entonces, dice, "corro alegremente a buscarlos". Puede que sean los pasos o las voces del redentor. $\mathrm{Si}$, en cambio, son muchachos y muchachas los matará, pero es que matarlos es parte de la ceremonia a que lo obliga el destino. 


\section{EL CUENTO COMO JUEGO}

En Los Anales de Buenos Aires, mayo-junio de 1947, Núm. 15-I6 se había publicado "La casa de Asterión". En julio, Núm. I7, apareció allí otro cuento de Borges, "El Zahir", dentro del cual el protagonista compone un relato fantástico de idéntico esquema. Con perífrasis enigmáticas se disimula que se está relaborando un mito de los Nibelungos. El relato, esta vez, corre en boca de la serpiente Fafnir. "La aparición de Sigurd corta bruscamente la historia". El protagonista-narrador califica su propio relato de "fruslería". ¿Es, de veras, una fruslería? Si es así ¿también será fruslería este cuento gemelo, La casa de Asterión? No hay duda que a Borges le divierte jugar con el lector, y que su técnica favorita es la del desenlace sorpresivo: contar hechos cuya interpretación sólo se ha de revelar en las últimas palabras. Pero ¿es su propósito lúdico, y nada más?

\section{EL TEMA DEL LABERINTO}

Reparemos, ante todo, en que su tema -el laberinto- es el más significativo en toda la obra de Borges. ${ }^{7}$ Casi no hay cuento, poema o ensayo en que no asome. Toda clase de laberintos. Laberintos como construcciones en el espacio o en el tiempo, como formas de la realidad o de la mente, como hechos o como alegorías. Más aún: hay cuentos construidos como laberintos, cuentos dentro de cuentos, cuentos que aunque a primera vista parezcan autónomos son en verdad pedazos de un gran laberinto que los atraviesa a todos. En El Aleph, por ejemplo, hay tres cuentos correlacionados. En "Abenjacán el Bojarí, muerto en su laberinto" el rector Allaby predica desde el púlpito un sermón con el tema del laberinto. Este sermón es el cuento "Los dos reyes y los dos laberintos" que le sigue. Pero en "Abenjacán el Bojari" hay dos personajes, Dunraven y Unwin, que platican sobre el Minotauro y su laberinto y complementan así "La casa de Asterión".

¿Por qué el tema del laberinto es una constante en la literatura de Borges? ¿Por qué? Porque responde a una cosmovisión.

\section{VISIÓN DEL MUNDO}

Para Borges el mundo es caos; y dentro del caos el hombre está perdido como en un laberinto. Sólo que el hombre, a su vez, es capaz de cons-

7 Véase Ana María Barrenechea, "Los símbolos del caos y del cosmos. Los laberintos (en La expresión de la irrealidad en la obra de Jorge Luis Borges. El Cólegio de México, 1957, pp. 57-60). 
truir laberintos propios. Laberintos mentales, con hipótesis que procuran explicar el misterio del otro laberinto, ése dentro del cual andamos per. didos.

En La casa de Asterión, a pesar de su brevedad (y a pesar de su pobreza) se tocan estos aspectos gnoseológicos y metafísicos del laberinto como símbolo del universo.

El Minotauro medita melancólicamente e imagina su laberinto multiplicado por la tierra y por el cielo:

También he meditado sobre la casa. Todas las partes de la casa están muchas veces, cualquier lugar es otro lugar. No hay un aljibe, un patio, un abrevadero, un pesebre; son catorce (son infinitos) los pesebres, abrevaderos, patios, aljibes. La casa es del tamaño del mundo; mejor dicho, es el mundo. Sin embargo, a fuerza de fatigar patios con un aljibe y polvorientas galerias de piedra gris he alcanzado la calle y he visto el templo de las Hachas y el mar. Eso no lo entendí hasta que una visión de la noche me reveló que también son catorce (son infinitos) los mates y los templos. Todo está muchas veces, catorce veces, pero dos cosas hay en el mundo que parecen estar una sola vez: arriba, el intrincado sol; abajo, Asterión. Quizá yo he creado las estrellas y el sol y la enorme casa, pero ya no me acuerdo.

Aquí se alude a otro de los temas que Borges suele desarrollar en sus cuentos: el de un dios tan caótico como su creación. Un dios, en este caso, que se ha olvidado de su creación. En otras palabras, que para com. prender el laberíntico y caótico universo en que estamos metidos no nos basta la idea de un dios, puesto que este dios puede ser también defectuoso, irracional y arbitrario. La ocurrencia de un dios insatisfactorio en los cuentos y ensayos de Borges es demasiado frecuente para citar sus casos aquí. Cuando el Minotauro, pensando en el redentor a quien espera, dice: "si mi oído alcanzara todos los rumores del mundo yo percibiría sus pasos", está repitiendo un tópico muy borgiano: una inteligencia divina podría ejemplificarse, dice, en la capacidad de percibir en una sola figura todos los pasos que ha dado un hombre (Otras inquisiciones, p. I49).

Borges adoptó, por ser artísticamente fecunda, la filosofía del idealismo absoluto. Cada conciencia fabrica su propia realidad e intenta darle un sentido. Hay pensadores que proponen hipótesis simples: Dios, la Materia... Borges prefiere complicar las suyas. Es radicalmente escéptico pero cree en la belleza de todas las teorías, las colecciona y al estirarlas hasta sus últimas consecuencias las reduce al absurdo. La agnóstica visión 
de Borges se expresa en una dialéctica de buen humor. Encierra en un laberinto lingüístico al lector y juega con él hasta derrotarlo. En su fruición estética se perciben, sin embargo, sobretonos de angustia, una angustia que dimana de saberse único, solitario, delirante, perdido y perplejo en un Ser ciego. Borges es Asterión, el Minotauro.

ENRIQUE ANDERSON IMBERT

The University of Micbigan

Ann Arbor, Micbigan 
